\title{
Organic carbon preservation promoted by aromatic compound-iron complexes through manure fertilization in red soil
}

\author{
Yunjie Wen ${ }^{1,2} \cdot$ Jiong Wen ${ }^{3} \cdot$ Qi Wang ${ }^{2} \cdot$ Lingyu Bai $^{1,2} \cdot$ Yanan Wang ${ }^{1,3} \cdot$ Shiming Su ${ }^{1,3} \cdot$ Cuixia Wu $\mathbf{W}^{1,3} \cdot$ Xibai Zeng $^{1,3}$ (D)
}

Received: 8 May 2020 / Accepted: 27 August 2020 / Published online: 12 September 2020

(C) Springer-Verlag GmbH Germany, part of Springer Nature 2020, corrected publication 2020

\begin{abstract}
Purpose This study was aimed at evaluating the effect of manure fertilization on organo-mineral complexes based on unfertilized (CK) and 5-year manure fertilization (M) in red soils (ultisols).

Materials and methods Sequential density fractionation was adopted to obtain particular organic matter $\left(\mathrm{POM},<1.8 \mathrm{~g} \mathrm{~cm}^{-3}\right)$ and mineral-associated organic matter $\left(1.8-2.2 \mathrm{~g} \mathrm{~cm}^{-3}\left(\mathrm{MOM}_{1.8-2.2}\right) ; 2.2-2.6\left(\mathrm{MOM}_{2.2-2.6}\right) ;>2.6\left(\mathrm{MOM}_{>} 2.6\right)\right.$ ), which were demineralized by hydrofluoric acid (HF). The HF-dissolved organic carbon (OC) was identified as mineral bound OC, and was characterized by comparing the band area of Fourier transform infrared spectroscopy before and after $10 \% \mathrm{HF}$ demineralization.

Results and discussion Manure fertilization significantly increased the OC and nitrogen contents of bulk soil, POM, $\mathrm{MOM}_{1.8-2.2}$, and $\mathrm{MOM}_{2.2-2.6}$, but did not affect $\mathrm{MOM}_{>2.6}$. About 82.9-86.1\% soil OC was retained by $\mathrm{MOM}_{1.8-2.2}$ and $\mathrm{MOM}_{2.2-2.6}$ dominated with iron (Fe) and aluminum oxides and phyllosilicates, in which HF-dissolved OC was significantly positively correlated with poorly crystalline $\left(\mathrm{Fe}_{\mathrm{o}}\right)\left(R^{2}=0.61, P<0.01\right)$ and organically complexed $\left(\mathrm{Fe}_{\mathrm{p}}\right) \mathrm{Fe}$ contents $\left(R^{2}=0.45, P<0.05\right)$. Moreover, the $\mathrm{Fe}_{\mathrm{o}}$ and $\mathrm{Fe}_{\mathrm{p}}$ contents were higher in $\mathrm{M}$ than in $\mathrm{CK}(P<0.05)$, and significantly negatively correlated with the reduction of aromatic $\mathrm{C}(\mathrm{M}$ had more reduction than $\mathrm{CK}$ ) following HF demineralization in $\mathrm{MOM}_{1.8-2.2}$ and $\mathrm{MOM}_{2.2-2.6}(P<0.05)$, indicating Fe bound $\mathrm{OC}$ was mainly aromatic $\mathrm{C}$. The quartz and feldspar-dominated $\mathrm{MOM}_{>} 2.6$ was composed of aromatic $\mathrm{C}$, amide $\mathrm{N}$, and polysaccharides, not being affected by fertilization.

Conclusions Our results suggested that manure fertilization promotes organo-mineral association, particularly for aromatic compound-Fe complexes, contributing to OC preservation in red soils.
\end{abstract}

Keywords Hydrofluoric acid $\cdot$ Sequential density fractionation $\cdot$ Poorly crystalline mineral oxides $\cdot$ Stabilizing mechanism

Responsible editor: Claudio Colombo

Electronic supplementary material The online version of this article (https://doi.org/10.1007/s11368-020-02769-y) contains supplementary material, which is available to authorized users.

Xibai Zeng

zengxibai@ caas.cn

1 Key Laboratory of Agro-Environment, The Ministry of Agriculture of China/Institute of Environment and Sustainable Development in Agriculture, Chinese Academy of Agricultural Sciences, No 12 Zhongguancun South Street, Beijing 100081, People's Republic of China

2 College of Natural Resources and Environment, Northwest A \& F University, Yangling 7122100, Shaanxi, China

3 Yueyang Agricultural Environment Scientific Experiment Station, Ministry of Agriculture, Yueyang 414000, China

\section{Introduction}

Red soils widely distributed in the tropical and subtropical regions of South China are characterized by relatively lower productivity and organic carbon (OC), which caused by severe weathering (e.g., abundant rainfall and high temperature) and intensive farming practices (Zhang et al. 2009). Soil organic carbon (SOC) plays a crucial role in cropland productivity, and its content has been included among the parameters in the guidelines for soil quality (Reeves 1997; Tong et al. 2014). Therefore, understanding the mechanisms of SOC preservation and stabilization in the context of manure fertilization of red soils is pivotal to keep the stability of agroecosystem in this region. 
SOC pool can be categorized into particulate organic matter (POM) and mineral-associated organic matter (MOM) according to their densities. These MOM are primarily important for long-term SOC preservation in soils because of these SOC absorbed around mineral having less accessible to microorganisms by forming a physical barrier between SOC and microorganisms (Torn et al. 1997; Lavallee et al. 2020). Interactions between minerals and $\mathrm{OC}$ are also affected by the soil mineral composition, fertilizer management, and climate condition (Six et al. 2002; Lal 2018). Red soil contains significant amounts of iron (Fe) and aluminum (Al) oxides and phyllosilicate minerals such as kaolinite, which play important roles in SOC preservation through the formation of MOM (Zhang et al. 2013; Bruun et al. 2010). Recent work indicated that the mineral oxides, especially amorphous or noncrystalline types, appear to more strongly interact with SOC based on cation bridges than just phyllosilicates (Mikutta et al. 2007). The capacity of mineral oxides to interact with SOC is controlled by soil physicochemical conditions (e.g., pH and redox potential) and exudates and metabolic compounds secreted from plant roots and microbes, whose activities are also affected by fertilization (Dakora and Phillips 2002; Colombo et al. 2014). Most studies found that manure fertilizer made more organic acids that act as complexing and reduction agents for mobilizing mineral, further promoting the production of noncrystalline types, which is beneficial for the formation of MOM (Yu et al. 2017; Huang et al. 2018). However, the formation of MOM between non-crystalline mineral oxides and specific organic compounds is still unclear. Wan et al. (2019) reported that Fe oxides were selectively associated with polysaccharides and aliphatic compounds in different types of agricultural soil. Zhao et al. (2016) considered that aromatic compounds were the main component of the organo-Fe complexes. Filimonova et al. (2016) also found that the allophane mainly imparts chemical protection to labile organic compounds, e.g., carbohydrates. Therefore, more accurately, evaluation of the contents and compositions of OC bound with different mineral species is needed to understand the dynamics and stabilization mechanisms of SOC following manure fertilization in red soil.

In recent years, many authors adopted the combination of physical and chemical fractionation methods to isolate these MOM effectively (Sleutel et al. 2009). Physical density fractionation can be used to isolate bulk soil into free POM (light fractions) and primary and secondary MOM (heavy fractions) depending on their different densities (Sollins et al. 2009; Wagai et al. 2015). The chemical method, such as the demineralization with hydrofluoric (HF) acid, has also been used to treat MOM for clarifying the binding mechanism between $\mathrm{OC}$ and mineral particles
(Helfrich et al. 2007). That is because enormous amounts of OC associated with minerals can be released during the HF demineralization procedure in metal oxide-rich soils, conversely, the non-mineral associated OC is almost unchanged (Rumpel et al. 2008). Sanderman et al. (2017) suggested that the HF demineralization procedure was best suited for characterizing OC that can be absorbed or precipitated with minerals, and the soil physicochemical environment should also be considered. To investigate the structures of MOM, several studies have physically isolated bulk soils into different density fractions, and then being demineralized with HF. Yeasmin et al. (2017a) suggested that HF demineralization was more suitable for analyzing the organic bands in the soil FTIR spectra than dry ashing and sodium hypochlorite oxidation because of the greatly increased organic bands without mineral interference spectra after HF treatment, and then concluded that the HF demineralization in conjunction with density fractions would be beneficial to study the structures of MOM through comparing the organic bonds of Fourier transform infrared (FTIR) spectroscopy before and after HF demineralization (Yeasmin et al. 2017a, b). Although these studies have used a wide range of soil types (i.e., ferralsols, luvisol, vertisol, and solonetz), few have made use of the above procedure to evaluate the manure fertilizer effects on the contents and compositions of MOM.

Considering all the above, this study was aimed at (i) determining the qualitative and quantitative distribution of MOMs, and (ii) investigating the specific organic functional groups bound with organo-mineral complexes following manure fertilization of red soils in southern China based on sequential density fractionation and HF demineralization.

\section{Materials and methods}

\subsection{Sites and soil samples}

Soil samples used in the present study were collected in midAugust 2018 from the Static Fertilization at Yueyang City, Hunan Province, in the Southwest China region (E $112^{\circ} 44^{\prime}$ $14^{\prime \prime}, \mathrm{N} 28^{\circ} 57^{\prime} 11^{\prime \prime}$ ) (Fig. 1), which was initiated in 2013 to study the effect of different amounts of swine manure on soil quality and environment. This site represents a typical agricultural region of subtropical China with red soil developed from quaternary red clay parent material, being classified as ultisols (Soil Survey Staff 2010). This area is affected by a warm and humid subtropical monsoon climate with annual precipitation of $1400 \mathrm{~mm}$ and annual average temperature of $17^{\circ} \mathrm{C}$. Prior to experiment, soil properties were $\mathrm{pH} 6.34,8.02 \mathrm{~g} \mathrm{~kg}^{-1} \mathrm{SOC}$, $1.05 \mathrm{~g} \mathrm{~kg}^{-1}$ total nitrogen $(\mathrm{N}), 10.32 \mathrm{mg} \mathrm{kg}^{-1}$ available $\mathrm{P}$, and $246.7 \mathrm{mg} \mathrm{kg}^{-1}$ available potassium (K). A full randomized 


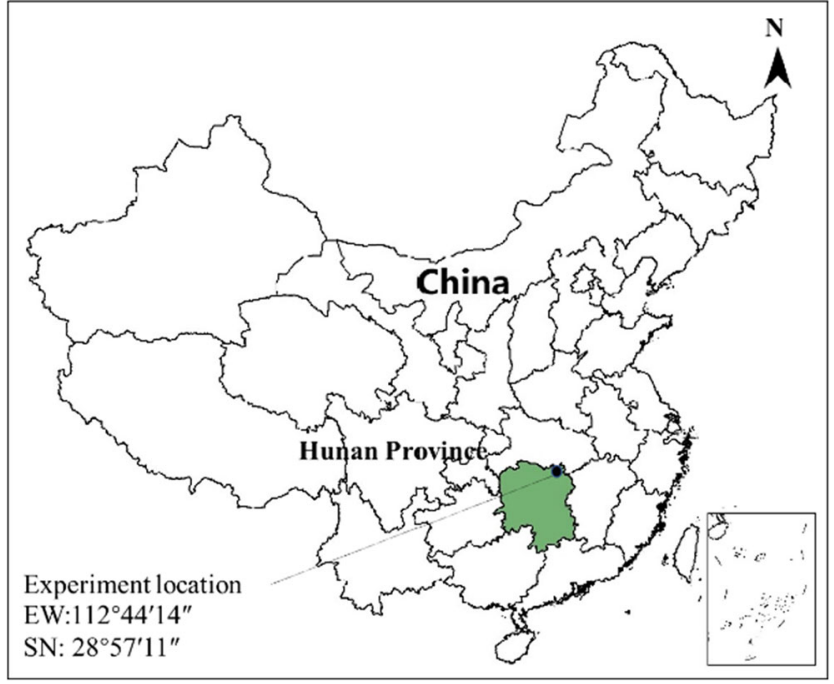

Fig. 1 Location of the study area

design with two different treatments (three replicates each) was carried out in 6 plots $(3 \mathrm{~m} \times 7 \mathrm{~m})$ under a maize-rape system. Maize was planted in late-April (spring) and harvested in mid-August (summer), while rape was planted in mid-October (autumn) and harvested in mid-April (spring) of the next year. Specifically, the two treatments were control $(\mathrm{CK})$ and swine manure treatment $(\mathrm{M})$. The $\mathrm{M}$ was annually applied as $15,000 \mathrm{~kg} \mathrm{hm}^{-2}$ swine manure that contained $139.3 \mathrm{~g} \mathrm{~kg}^{-1} \mathrm{OC}, 15.3 \mathrm{~g} \mathrm{~kg}^{-1} \mathrm{~N}, 14.9 \mathrm{~g} \mathrm{~kg}^{-1} \mathrm{P}_{2} \mathrm{O}_{5}, 11.3 \mathrm{~g}$ $\mathrm{kg}^{-1} \mathrm{~K}_{2} \mathrm{O}$, and $60 \% \mathrm{H}_{2} \mathrm{O}$. The maize and rape straws did not return to the field after harvest. In each plot, five soil samples were randomly collected using a core sampler $(20 \mathrm{~cm}$ high and with a $5-\mathrm{cm}$ diameter) from 0 to $20 \mathrm{~cm}$ depth and mixed to form a composite sample. Soil samples were air-dried and passed through a $2-\mathrm{mm}$ sieve to remove some visible plant residues, and the remains of visible plant residues were removed with tweezers, thereby minimizing the influence of plant residues on further chemical analysis.

\subsection{Sequential density fractionation}

The sequential density fractionation (SDF) method was used to separate bulk soil into four density fractions (Yeasmin et al. $2017 \mathrm{~b}):<1.8$ (POM), 1.8-2.2 ( MOM $\left._{1.8-2.2}\right), 2.2-2.6$ $\left(\mathrm{MOM}_{2.2-2.6}\right)$, and $>2.6 \mathrm{~g} \mathrm{~cm}^{-3}\left(\mathrm{MOM}_{>} 2.6\right)$. Firstly, $15 \mathrm{~g}$ of air-dried soil and $50 \mathrm{~mL}$ of $1.8 \mathrm{~g} \mathrm{~cm}^{-3}$ sodium polytungstate (SPT) solution were mixed into a $100-\mathrm{mL}$ centrifuge tube. The mixture was shaken for $3 \mathrm{~h}$ and then centrifuged $(15 \mathrm{~min}$, $2973 \mathrm{~g})$. The POM $\left(<1.8 \mathrm{~g} \mathrm{~cm}^{-3}\right)$ was collected on a $0.45-\mu \mathrm{m}$ membrane filter. These steps were repeated three times to ensure a full recovery. The POM was rinsed with deionized water until salt concentration reached $<50 \mathrm{mS}$ $\mathrm{cm}^{-1}$. The remaining sediment in the centrifuge tube was mixed with $50 \mathrm{~mL} 2.2 \mathrm{~g} \mathrm{~cm}^{-3}$ SPT solution, following the same procedure as POM to obtain the $\mathrm{MOM}_{1.8-2.2}$. Similarly, the residual sediment after removing $\mathrm{MOM}_{1.8-2.2}$ was mixed with $50 \mathrm{~mL} 2.6 \mathrm{~g} \mathrm{~cm}^{-3} \mathrm{SPT}$ solution to obtain the $\mathrm{MOM}_{2.2-2.6}$ (supernatant), and $\mathrm{MOM}_{>} 2.6$ (precipitate). All recovered fractions were oven-dried at $40{ }^{\circ} \mathrm{C}$ and ground to a fine powder for further analyses.

\subsection{Removal of mineral bound OC with HF}

Mineral bound OC in the four density fractions was removed by the HF demineralization procedure (Kaiser et al. 2002). About 200-250 mg of sample was weighed into a $25-\mathrm{mL}$ centrifuge tube and $10 \mathrm{~mL} 10 \% \mathrm{HF}$ was added into the tube, shaken for $2 \mathrm{~h}$ and centrifuged, and the supernatant was decanted. Every sample was washed using 10\% HF 4-6 times to remove minerals completely. The residues were rinsed 5 times with deionized water and then oven-dried at $40{ }^{\circ} \mathrm{C}$, weighted, ground, and stored in glass vials for further FTIR and $\mathrm{C}$ and $\mathrm{N}$ analyses.

\subsection{Mineralogy and chemical analyses}

Mineralogical compositions of the $\mathrm{MOM}_{1.8-2.2}, \mathrm{MOM}_{2.2-2.6}$, and $\mathrm{MOM}_{>2.6}$ fractions were characterized using X-ray diffraction (XRD) with $\mathrm{Cu} \mathrm{K} \alpha$ radiation at $40 \mathrm{kV}$ and $40 \mathrm{~mA}$ (PANalytical, Netherlands) as previously described (Yeasmin et al. 2017b). These density fractions were ground to fine powder and were scanned from 5 to $45^{\circ}$ at a speed of $1^{\circ}$ $\min ^{-1}$ with a step size of $0.01^{\circ}$.

The quantification of poorly crystalline $\mathrm{Fe}$ and $\mathrm{Al}$ oxides $\left(\mathrm{Fe}_{\mathrm{o}}\right.$ and $\left.\mathrm{Al}_{\mathrm{o}}\right)$ is achieved using ammonium oxalate $(\mathrm{pH}=3)$ with a soil to solution ratio of 1:50 and shaken for $2 \mathrm{~h}$ in the dark. The organically complex $\mathrm{Fe}$ and $\mathrm{Al}$ oxides $\left(\mathrm{Fe}_{\mathrm{p}}\right.$ and $\left.\mathrm{Al}_{\mathrm{p}}\right)$ were quantified by sodium pyrophosphate $(\mathrm{pH} 10.0)$ with a soil to solution ratio of 1:10 and shaken for $16 \mathrm{~h}$ (McKeague et al. 1971). Fe and $\mathrm{Al}$ in the two extracts were determined using inductively coupled plasma mass spectrometry (ICP-MS) (Agilent 7500CX).

Soil $\mathrm{pH}$ was measured with a compound electrode at a soil to water ratio of $1: 2.5$. Available $\mathrm{P}$ was extracted using $0.5 \mathrm{M}$ sodium bicarbonate $(\mathrm{pH}=8.5)$, in which the $\mathrm{P}$ content was measured by molybdenum blue colorimetry. Available K was extracted using $1 \mathrm{~mol} \mathrm{~L}^{-1}$ ammonium acetate $(\mathrm{pH}=7)$ and measured by a flame photometer (Thermo Scientific iCE 3500).

Total OC and $\mathrm{N}$ of bulk soil and the untreated and HF-treated density fractions and the natural $\delta^{13} \mathrm{C}$ of untreated density fractions were determined using isotope ratio mass spectrometry (Vario PYRO cube-IsoPrime 100). The proportion and content of HF-dissolved OC or $\mathrm{N}$ were calculated as follows (Yeasmin et al. 2017b): 
the proportion of HF dissolved OC $($ or $\mathrm{N})(\%$ of initial $)=\left[\frac{\left(\text { Mass }_{\text {initial }} \times \mathrm{OC}_{\text {initial }}\right)-\left(\mathrm{Mass}_{\mathrm{HF}} \times \mathrm{OC}_{\mathrm{HF}}\right)}{\left(\mathrm{Mass}_{\text {initial }} \times \mathrm{OC}_{\text {initial }}\right)}\right] \times 100$

the content of HF dissolved OC $($ or N $)\left(\mathrm{g} \mathrm{kg}^{-1}\right.$ fraction $)=\left[\frac{\left(\text { Mass }_{\text {initial }} \times \mathrm{OC}_{\text {initial }}\right)-\left(\mathrm{Mass}_{\mathrm{HF}} \times \mathrm{OC}_{\mathrm{HF}}\right)}{\left(\text { Mass }_{\text {initial }}-\mathrm{Mass}_{\mathrm{HF}}\right)}\right]$

where Mass $_{\text {initial }}=$ initial weight $(\mathrm{kg})$ of the density fractions, Mass $_{\mathrm{HF}}=$ residual weight $(\mathrm{kg})$ of the density fractions after HF demineralization, OC $(\text { or } N)_{\text {initial }}=\mathrm{OC}(\mathrm{N})$ content $(\mathrm{g}$ $\mathrm{kg}^{-1}$ ) of the initial the density fractions, and $\mathrm{OC}(\text { or N })_{\mathrm{HF}}=$ $\mathrm{OC}(\mathrm{N})$ content $\left(\mathrm{g} \mathrm{kg}^{-1}\right)$ of the density fractions after $\mathrm{HF}$ demineralization.

\subsection{Diffuse reflectance Fourier transform spectroscopy}

The untreated and HF-treated density fractions were used for FTIR analyses. Briefly, $1.0 \mathrm{mg}$ of dried samples was accurately diluted with $200 \mathrm{mg} \mathrm{KBr}$, finely ground, and fully homogenized. The spectra were recorded following 32 scans with a resolution of $4 \mathrm{~cm}^{-1}$ in the $400-4000 \mathrm{~cm}^{-1}$ wavenumber range on an FTIR spectrometer (Bruker Vertex $70 \mathrm{~V}$, Bruker Optics, Germany). $\mathrm{KBr}$ background spectra were collected and subtracted from the sample spectra.

All spectra were normalized. The main assignments in FTIR spectra were as follows: $\mathrm{OH}$ of phyllosilicates and $\mathrm{Fe} /$ Al oxides (3700-3440 $\left.\mathrm{cm}^{-1}\right)$, aliphatic C $\left(3010-2800 \mathrm{~cm}^{-1}\right)$, aromatic C $\left(1680-1580 \mathrm{~cm}^{-1}\right)$, amide $\mathrm{N}\left(1546-1520 \mathrm{~cm}^{-1}\right)$, and polysaccharide $\mathrm{C}\left(1175-1148 \mathrm{~cm}^{-1}\right)$, which were integrated to calculate the relative peak areas using the software OPUS version 6.5 (Table S1) (Demyan et al. 2012; Yeasmin et al. 2017b). Relative band area of these four organic functional groups was calculated as follows (Demyan et al. 2012):

Relative band area $=\frac{\text { Area of a certain band }}{\text { Sum of the area of all bands }}$

The changes of the relative band area in these four organic functional groups after HF demineralization were determined by comparing the relative band areas of HF-treated density fractions with the relevant untreated. According to Yeasmin et al. (2017b), the increases and decreases in relative band area indicated organic functional groups were bound with minerals and non-bound respectively. The change of relative band area in the organic functional groups was calculated as follows:

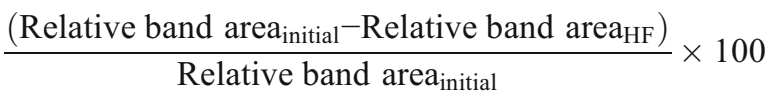

where relative band area $_{\mathrm{HF}}=$ relative band area of the organic functional groups in the residue density fractions after HF demineralization and relative band area $_{\text {initial }}=$ relative band area of the organic functional groups in the initial density fractions.

\subsection{Statistical analysis}

Statistical analyses were performed with SPSS 19.0. The analysis of variance was used to determine a statistically significant difference $(P<0.05)$ between the $\mathrm{CK}$ and $\mathrm{M}$ treatments. The correlation between the proportion of HF-dissolved OC and the corrected band area of phyllosilicates or $\mathrm{Fe}$ and $\mathrm{Al}$ oxide band was obtained with the SigmaPlot (12.5) software.

\section{Results}

\subsection{General characteristics of bulk soils}

Manure fertilization (M) significantly increased soil $\mathrm{pH}$ (6.65), SOC (9.32 $\left.\mathrm{g} \mathrm{kg}^{-1}\right)$, total $\mathrm{N}\left(1.38 \mathrm{~g} \mathrm{~kg}^{-1}\right)$, available $\mathrm{P}\left(32.8 \mathrm{mg} \mathrm{kg}^{-1}\right)$, and $\mathrm{K}\left(328.3 \mathrm{mg} \mathrm{kg}^{-1}\right)$ contents $(P<0.05)$. In the $\mathrm{CK}$, soil $\mathrm{pH}$ value was 6.13 , SOC and total $\mathrm{N}$ contents were 7.18 and $1.02 \mathrm{~g} \mathrm{~kg}^{-1}$ respectively, and available $\mathrm{P}$ and $\mathrm{K}$ were 7.8 and $247.2 \mathrm{mg}$ $\mathrm{kg}^{-1}$ respectively (Table $\mathrm{S} 2$ ).

\subsection{Mineral compositions of MOM}

The XRD results for $\mathrm{MOM}_{1.8-2.2}, \mathrm{MOM}_{2.2-2.6}$, and $\mathrm{MOM}_{>2.6}$ are presented in Fig. 2. The $\mathrm{MOM}_{1.8-2.2}$ and $\mathrm{MOM}_{2.2-2.6}$ had similar mineral composition, being mainly composed of illite, kaolinite, and iron and aluminum minerals (i.e., gibbsite, goethite, and hematite). The $\mathrm{MOM}_{>} 2.6$ was mainly consisted of quartz and feldspars. Meanwhile, the $\mathrm{Fe}_{\mathrm{o}}$ and $\mathrm{Fe}_{\mathrm{p}}$ contents of the M (3.97 and $4.93 \mathrm{~g} \mathrm{~kg}^{-1}$ for $\mathrm{Fe}_{\mathrm{o}} ; 0.59$ and $0.73 \mathrm{~g} \mathrm{~kg}^{-1}$ for $\mathrm{Fe}_{\mathrm{p}}$ in $\mathrm{MOM}_{1.8-2.2}$ and $\mathrm{MOM}_{2.2-2.6}$ respectively) were greater than that of the CK (3.36 and $3.94 \mathrm{~g} \mathrm{~kg}^{-1}$ for $\mathrm{Fe}_{\mathrm{o}} ; 0.27$ and $0.34 \mathrm{~g} \mathrm{~kg}^{-1}$ for $\mathrm{Fe}_{\mathrm{p}}$ in $\mathrm{MOM}_{1.8-2.2}$ and $\mathrm{MOM}_{2.2-2.6}$ respectively) in $\mathrm{MOM}_{1.8-2.2}$ and $\mathrm{MOM}_{2.2-2.6}(P<0.05)$, showing a gradually increasing trend from $\mathrm{MOM}_{1.8-2.2}$ to $\mathrm{MOM}_{2.2-2.6}(P<0.05)$. However, the $\mathrm{Al}_{\mathrm{o}}$ and $\mathrm{Al}_{\mathrm{p}}$ had no consistent patterns in $\mathrm{MOM}_{1.8-2.2}$ and $\mathrm{MOM}_{2.2-2.6}$. The $\mathrm{Fe}_{\mathrm{o}}, \mathrm{Fe}_{\mathrm{p}}, \mathrm{Al}_{\mathrm{o}}$, and $\mathrm{Al}_{\mathrm{p}}$ contents were the lowest in 


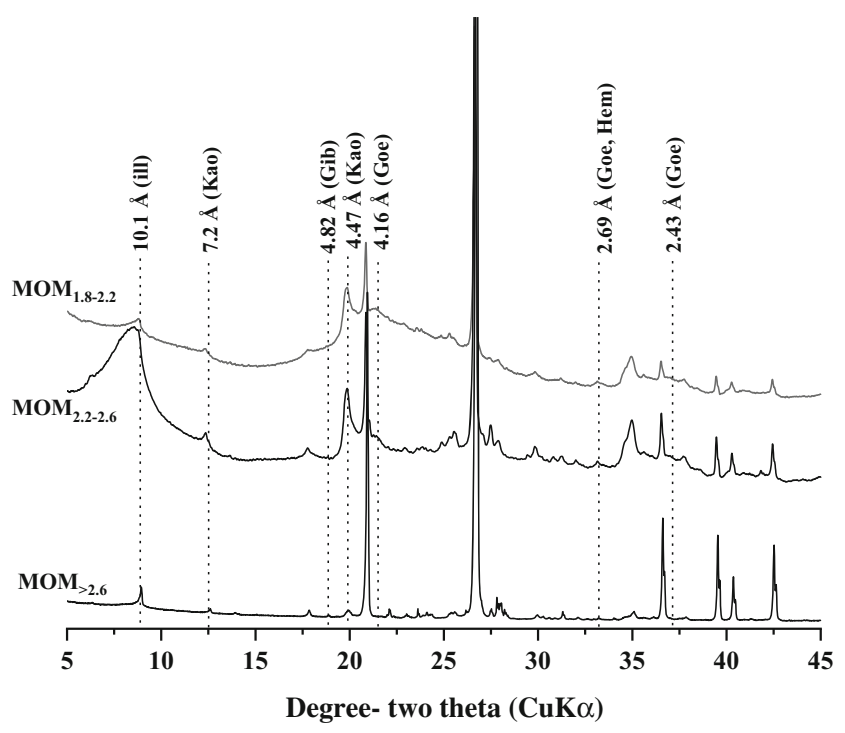

Fig. 2 X-ray powder diffraction patterns of the density fractions. MOM, mineral-associated organic matter. $\operatorname{MOM}_{1.8-2.2}\left(1.8-2.2 \mathrm{~g} \mathrm{~cm}^{-3}\right)$, $\mathrm{MOM}_{2.2-2.6}\left(2.2-2.6 \mathrm{~g} \mathrm{~cm}^{-3}\right), \mathrm{MOM}_{>2.6}\left(>2.6 \mathrm{~g} \mathrm{~cm}^{-3}\right)$. Ill = illite, $\mathrm{Kao}=$ kaolinite, $\mathrm{Gib}=$ gibbsite, Goe $=$ goethite, $\mathrm{Hem}=$ hematite

$\mathrm{MOM}_{>2.6}(P<0.05)$ and had no difference between the $\mathrm{M}$ and $\mathrm{CK}(P>0.05)$ (Fig. 3).

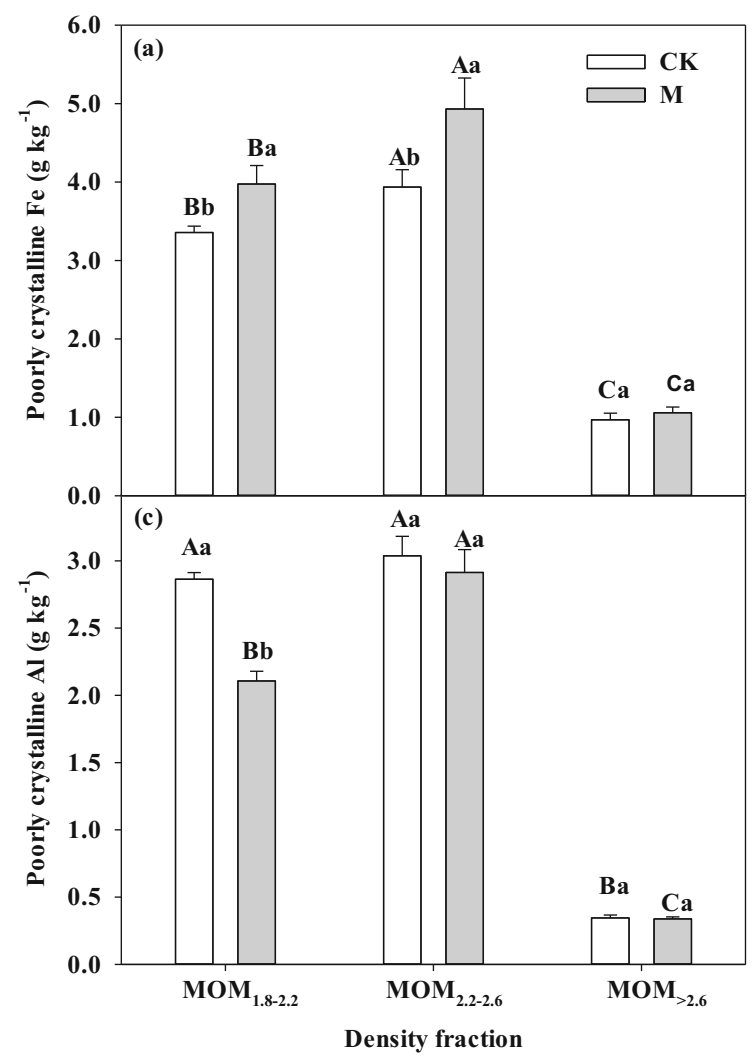

Fig. 3 Mean values of poorly crystalline iron $(\mathrm{Fe})$ and aluminum (Al) oxides and organically complexed $\mathrm{Fe}$ and $\mathrm{Al}$ oxides in MOM of control $(\mathrm{CK})$ and manure $(\mathrm{M})$ treatments. MOM, mineral-associated organic matter. $\mathrm{MOM}_{1.8-2.2}\left(1.8-2.2 \mathrm{~g} \mathrm{~cm}^{-3}\right), \mathrm{MOM}_{2.2-2.6}\left(2.2-2.6 \mathrm{~g} \mathrm{~cm}^{-3}\right), \mathrm{MOM}_{>}$ $2.6\left(>2.6 \mathrm{~g} \mathrm{~cm}^{-3}\right)$. Different uppercase and lowercase letters on the top of

\subsection{OC, N, $\delta^{13} \mathrm{C}$, and FTIR in POM and MOM}

The $\mathrm{Fe}$ and $\mathrm{Al}$ oxides and phyllosilicate-dominated $\mathrm{MOM}_{1.8-2.2}$ and $\mathrm{MOM}_{2.2-2.6}$ had the highest proportion $(60 \%)$ on a mass basis and retained substantial OC $(82.9-86.1 \%)$ and $\mathrm{N}(85.8-87.9 \%)$ of bulk soil in both treatments $(P<0.05)$, and the quartz and feldspar-dominated $\mathrm{MOM}_{>} 2.6$ with $37.2-38.9 \%$ proportion of soil mass had the lowest proportion of OC (4.6$4.7 \%)$ and $N(7.19-8.68 \%)(P<0.05)$ (Table 1$)$. The $\delta^{13} \mathrm{C}$ value showed an increasing trend from POM to $\mathrm{MOM}_{2.2-2.6}$, ranged from -23.3 to $-20.5 \%$ o $(P<$ $0.05)$ (Fig. 4a). Total OC $\left(0.82-0.86 \mathrm{~g} \mathrm{~kg}^{-1}\right)$ and $\mathrm{N}$ $\left(0.26-0.28 \mathrm{~g} \mathrm{~kg}^{-1}\right)$ contents were the lowest in the $\mathrm{MOM}_{>2.6}(P<0.05)$ and then gradually increased with decreasing density $(P<0.05)$. The $\mathrm{M}$ showed higher $\mathrm{OC}$ and $\mathrm{N}$ contents in the POM, $\mathrm{MOM}_{1.8-2.2}$, and $\mathrm{MOM}_{2.2-2.6}\left(223.5,102.6\right.$, and $9.9 \mathrm{~g} \mathrm{~kg}^{-1}$ for OC; $16.9,9.6$, and $1.9 \mathrm{~g} \mathrm{~kg}^{-1}$ for $\mathrm{N}$ in POM, $\mathrm{MOM}_{1.8-2.2}$, and $\mathrm{MOM}_{2.2-2.6}$ respectively) compared with the CK (124.4, 59.6, and $8.8 \mathrm{~g} \mathrm{~kg}^{-1}$ for OC; $8.5,5.4$, and $1.7 \mathrm{~g} \mathrm{~kg}^{-1}$ for $\mathrm{N}$ in $\mathrm{POM}, \mathrm{MOM}_{1.8-2.2}$, and $\mathrm{MOM}_{2.2-}$ 2.6 respectively) $(P<0.05)$ (Fig. $4 \mathrm{~b}$ and $\mathrm{d})$. The

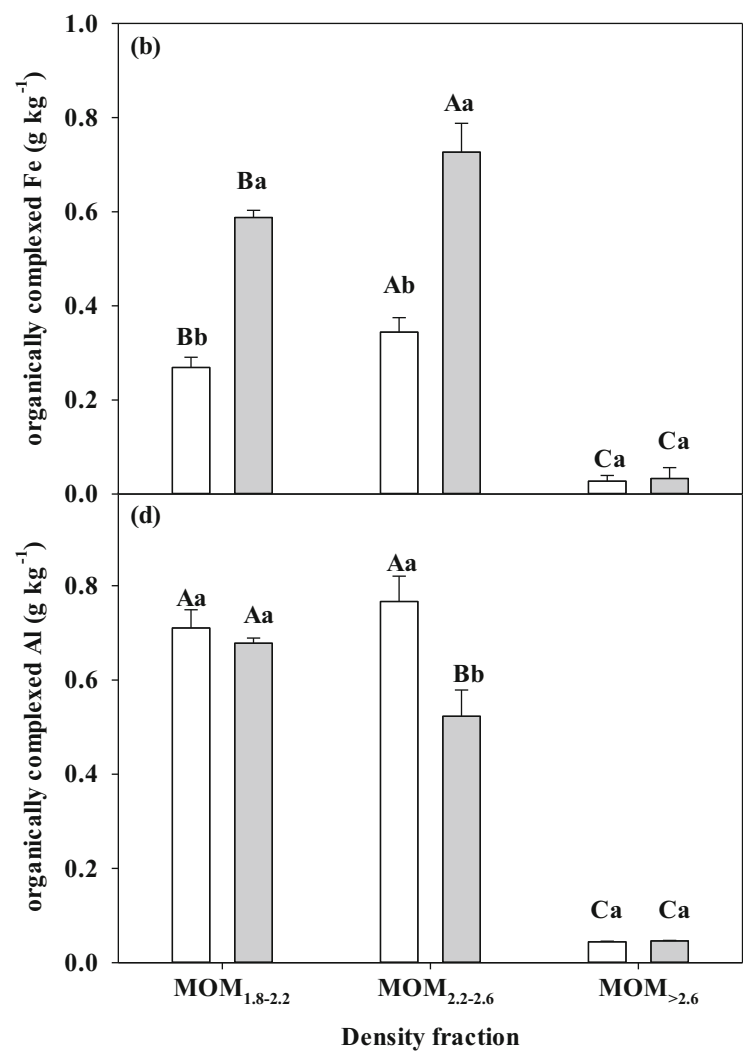

the error bars indicate the significant difference among different density fractions (POM vs. MOMs) at the same treatment and between the two treatments (CK vs. M) at the same density fraction, respectively $(P<$ $0.05)$. Error bars represent the standard error $(n=3)$ of a treatment 
Table 1 Proportion of soil mass, organic carbon (OC), and nitrogen $(\mathrm{N})$ of their total contents in the four density fractions of control (CK) and manure (M) treatments

\begin{tabular}{|c|c|c|c|c|}
\hline \multirow[t]{2}{*}{ Treatments } & \multirow[t]{2}{*}{ Density fractions } & \multicolumn{3}{|c|}{ Proportion of the total in soil $(\%)$} \\
\hline & & Mass & $\mathrm{OC}$ & $\mathrm{N}$ \\
\hline \multirow[t]{5}{*}{$\mathrm{CK}$} & POM & $0.5 \pm 0.03 \mathrm{Ca}$ & $9.1 \pm 0.6 \mathrm{Bb}$ & $3.4 \pm 0.3 \mathrm{Cb}$ \\
\hline & $\mathrm{MOM}_{1.8-2.2}$ & $1.0 \pm 0.11 \mathrm{Ca}$ & $8.3 \pm 0.9 \mathrm{Bb}$ & $4.3 \pm 0.8 \mathrm{Cb}$ \\
\hline & $\mathrm{MOM}_{2.2-2.6}$ & $59.3 \pm 1.63 \mathrm{Aa}$ & $77.8 \pm 1.7 \mathrm{Aa}$ & $83.6 \pm 1.9 \mathrm{Aa}$ \\
\hline & $\mathrm{MOM}_{>2.6}$ & $38.9 \pm 1.54 \mathrm{Ba}$ & $4.7 \pm 0.3 \mathrm{Ca}$ & $8.7 \pm 0.8 \mathrm{Ba}$ \\
\hline & Total recovery & $98.3 \pm 0.25$ & $94.1 \pm 2.36$ & $106.3 \pm 2.7$ \\
\hline \multirow[t]{5}{*}{ M } & POM & $0.6 \pm 0.03 \mathrm{Ca}$ & $13.3 \pm 0.7 \mathrm{Ca}$ & $7.0 \pm 0.1 \mathrm{Ca}$ \\
\hline & $\mathrm{MOM}_{1.8-2.2}$ & $1.3 \pm 0.02 \mathrm{Ca}$ & $15.2 \pm 0.1 \mathrm{Ba}$ & $8.6 \pm 0.1 \mathrm{Ba}$ \\
\hline & $\mathrm{MOM}_{2.2-2.6}$ & $60.6 \pm 1.44 \mathrm{Aa}$ & $67.7 \pm 1.9 \mathrm{Ab}$ & $77.2 \pm 0.7 \mathrm{Ab}$ \\
\hline & $\mathrm{MOM}_{>2.6}$ & $37.2 \pm 1.52 \mathrm{Ba}$ & $3.8 \pm 0.3 \mathrm{Db}$ & $7.2 \pm 0.7 \mathrm{Cb}$ \\
\hline & Total recovery & $98.4 \pm 0.41$ & $95.1 \pm 2.9$ & $103.8 \pm 2.1$ \\
\hline
\end{tabular}

Density fractions: $\operatorname{POM}\left(<1.8 \mathrm{~g} \mathrm{~cm}^{-3}\right), \mathrm{MOM}_{1.8-2.2}\left(1.8-2.2 \mathrm{~g} \mathrm{~cm}^{-3}\right), \mathrm{MOM}_{2.2-2.6}\left(2.2-2.6 \mathrm{~g} \mathrm{~cm}^{-3}\right)$, and MOM $>2.6\left(>2.6 \mathrm{~g} \mathrm{~cm}^{-3}\right)$. Different uppercase and lowercase letters indicate the significant difference among different density fractions (POM vs. MOM) at the same treatment and between the two treatments (CK vs. M) at the density fractions, respectively $(P<0.05)$. Values are means $(n=3)$ with standard error

$P O M$ particular organic matter, $M O M$ mineral-associated organic matter

changing trend of $\mathrm{C}: \mathrm{N}$ ratio was similar to the $\mathrm{OC}$ and $\mathrm{N}$ contents $(P<0.05)$ (Fig. 4c).

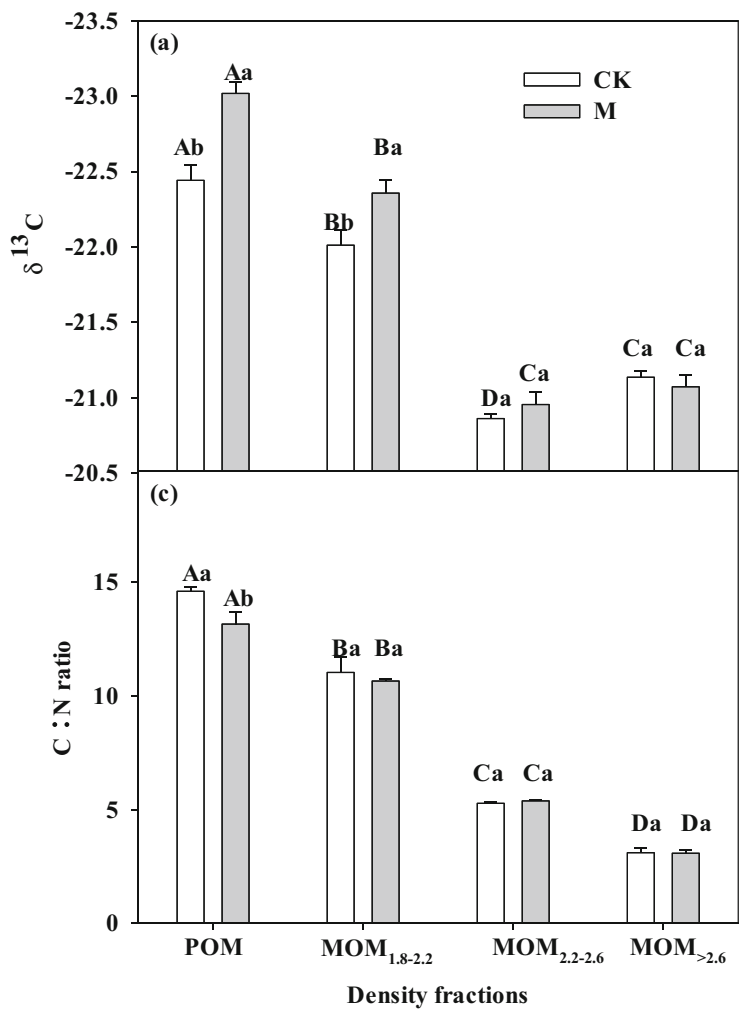

Fig. $4 \delta^{13} \mathrm{C}(\mathbf{a})$, total OC (b), C:N ratio (c), and total $\mathrm{N}(\mathbf{d})$ of the four density fractions following the control (CK) and manure (M) treatments obtained from mass spectroscopy. POM, particular organic matter $(<$ $\left.1.8 \mathrm{~g} \mathrm{~cm}^{-3}\right)$, MOM, mineral-associated organic matter. $\mathrm{MOM}_{1.8-2.2}$ $\left(1.8-2.2 \mathrm{~g} \mathrm{~cm}^{-3}\right), \mathrm{MOM}_{2.2-2.6}\left(2.2-2.6 \mathrm{~g} \mathrm{~cm}^{-3}\right)$, and $\mathrm{MOM}_{>2.6}(>2.6 \mathrm{~g}$
The FTIR spectra in these four organic functional groups before and after HF demineralization are presented in Fig. S1.

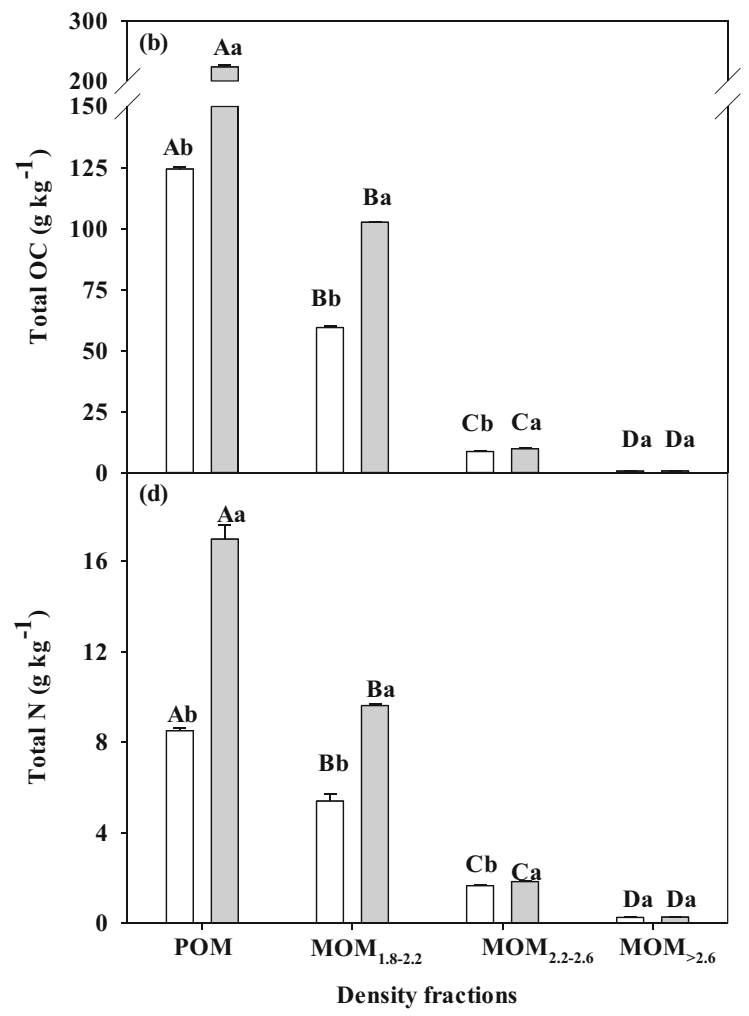

$\mathrm{cm}^{-3}$ ). Different uppercase and lowercase letters on the top of the error bars indicate the significant difference among different density fractions (POM vs. MOMs) at the same treatment and between the two treatments (CK vs. M) at the same density fraction, respectively $(P<0.05)$. Error bars represent the standard error $(n=3)$ of a treatment 
The relative area of aliphatic $\mathrm{C}\left(2930 \mathrm{~cm}^{-1}\right)$ had a downward trend with higher density (Fig. 5a). On the contrary, the aromatic $\mathrm{C}\left(1620 \mathrm{~cm}^{-1}\right)$ showed an increasing trend from POM to $\mathrm{MOM}_{>2.6}$ (Fig. 5b). These results led to the difference in aromatic $\mathrm{C}$ :aliphatic $\mathrm{C}$ ratio among $\mathrm{POM}$ and $\mathrm{MOM}$, showing an increasing tendency from $\mathrm{MOM}_{1.8-2.2}$ to $\mathrm{MOM}_{>2.6}$, with a higher value for the $\mathrm{M}$ in $\mathrm{MOM}_{2.2-2.6}$ and $\mathrm{MOM}_{>2.6}$ (Fig. 5e). Amide $\mathrm{N}\left(1530 \mathrm{~cm}^{-1}\right)$ and polysaccharides $\left(1159 \mathrm{~cm}^{-1}\right)$ increased with higher density (Fig. 5c, d).

\subsection{HF-dissolved OM in POM and MOM}

The significantly positive relationship between the proportion of HF-dissolved OC (\%) and the corrected band area of Fe and $\mathrm{Al}$ oxides and phyllosilicates $\left(R^{2}=0.83, P<0.01\right)$ (Fig. 6) confirmed that the HF-dissolved OC was associated with clay minerals. The HF demineralization caused a loss of about $31.2-58.8 \%$ OC from $\mathrm{MOM}_{1.8-2.2}$ and $\mathrm{MOM}_{2.2-2.6}$, with the smaller loss occurring in POM $(6.3-10.1 \%)$ and $\mathrm{MOM}_{>} 2.6$ (12.8-17.7\%) (Table 2). In $\mathrm{MOM}_{1.8-2.2}$ and $\mathrm{MOM}_{2.2-2.6}$, significantly positive correlations were found between HFdissolved OC $(\%)$ and poorly crystalline $\left(R^{2}=0.61, P<\right.$ $0.01)$ and organically complexed $\mathrm{Fe}\left(R^{2}=0.45, P<0.05\right)$ not Al (Fig. 8a, b). Meanwhile, the contents of HF-dissolved OC and $\mathrm{N}\left(\mathrm{g} \mathrm{kg}^{-1}\right)$ in $\mathrm{MOM}_{1.8-2.2}$ and $\mathrm{MOM}_{2.2-2.6}$ were greater in the M (39.01 and $6.45 \mathrm{~g} \mathrm{~kg}^{-1}$ for OC; 4.30 and $1.47 \mathrm{~g}$ $\mathrm{kg}^{-1}$ for $\mathrm{N}$ in $\mathrm{MOM}_{1.8-2.2}$ and $\mathrm{MOM}_{2.2-2.6}$ respectively) compared with that in the CK (21.70 and $4.70 \mathrm{~g} \mathrm{~kg}^{-1}$ for OC; 2.99 and $1.21 \mathrm{~g} \mathrm{~kg}^{-1}$ for $\mathrm{N}$ in $\mathrm{MOM}_{1.8-2.2}$ and $\mathrm{MOM}_{2.2-2.6}$ respectively) $(P<0.05)$ (Table 2).

In the MOM of both treatments, the change of the relative band area of aliphatic C $\left(2930 \mathrm{~cm}^{-1}\right)$ showed a gradual increment with increasing density after HF demineralization (Fig. $7 \mathrm{a}$. The reduction in the relative band area of aromatic $\mathrm{C}$ $\left(1620 \mathrm{~cm}^{-1}\right)$ after HF demineralization occurred in $\mathrm{MOM}_{1.8-}$ ${ }_{2.2}, \mathrm{MOM}_{2.2-2.6}$, and $\mathrm{MOM}_{>2.6}$, and the $\mathrm{M}$ had more reduction than the CK (Fig. 7b). Moreover, the significantly negative correlations were observed between the relative band change of aromatic $\mathrm{C}(\%)$ and the Fe oxide contents $\left(R^{2}=\right.$ $0.72, P<0.01$ for poorly crystalline $\mathrm{Fe} ; R^{2}=0.49, P<0.05$ for organically complexed $\mathrm{Fe}$ ) in $\mathrm{MOM}_{1.8-2.2}$ and $\mathrm{MOM}_{2.2-2.6}$ (Fig. 8c, d). The change of amide $\mathrm{N}\left(1530 \mathrm{~cm}^{-1}\right)$ band area increased in $\mathrm{MOM}_{1.8-2.2}$ and $\mathrm{MOM}_{2.2-2.6}$ after HF demineralization and then decreased in $\mathrm{MOM}_{>2.6}$ (Fig. 7c). The polysaccharide band area $\left(1159 \mathrm{~cm}^{-1}\right)$ was depleted in $\mathrm{MOM}_{2.2-2.6}$ and $\mathrm{MOM}_{>2.6}$ after $\mathrm{HF}$ demineralization, and the $\mathrm{M}$ had more depletion than the $\mathrm{CK}$ in $\mathrm{MOM}_{2.2-2.6}$ (Fig. 7d).

\section{Discussion}

\subsection{Organo-mineral complex distribution and composition in MOM}

The SDF effectively isolated the bulk soil into POM, Fe, and $\mathrm{Al}$ oxides and phyllosilicate-dominated $\mathrm{MOM}_{1.8-2.2}$ and

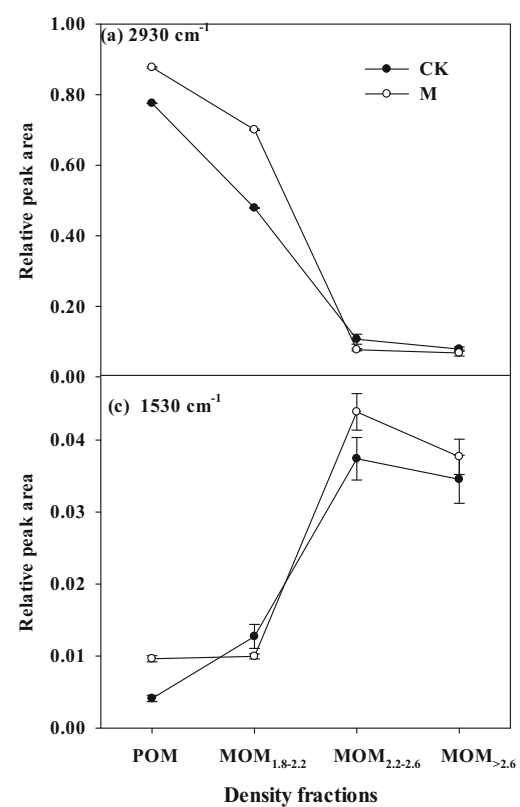

Fig. 5 Relative band area of organic groups (a-d) and ratio of $1620 \mathrm{~cm}^{-1}$ and $2930 \mathrm{~cm}^{-1}$ (e) band area in the infrared Fourier transform spectra of the four density fractions of control $(\mathrm{CK})$ and manure $(\mathrm{M})$ treatments. POM, particular organic matter $\left(<1.8 \mathrm{~g} \mathrm{~cm}^{-3}\right)$; MOM, mineral-associated organic matter. $\mathrm{MOM}_{1.8-2.2}\left(1.8-2.2 \mathrm{~g} \mathrm{~cm}^{-3}\right), \mathrm{MOM}_{2.2-2.6}(2.2-2.6 \mathrm{~g}$
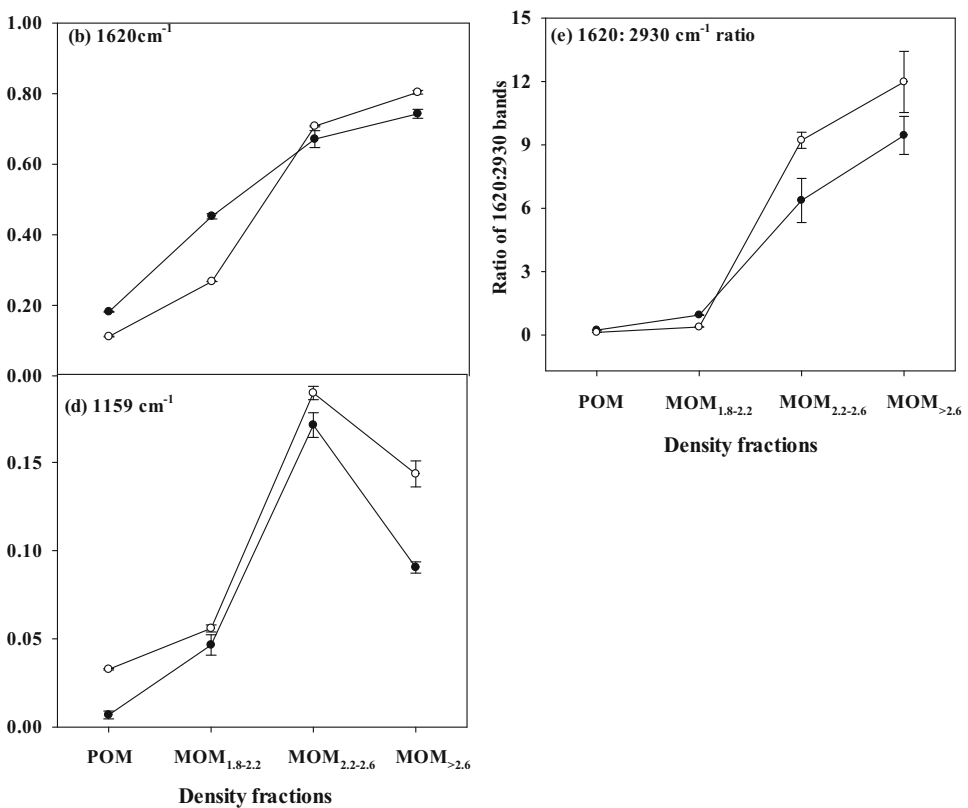

$\left.\mathrm{cm}^{-3}\right)$, and $\mathrm{MOM}_{>2.6}\left(>2.6 \mathrm{~g} \mathrm{~cm}^{-3}\right)$. Aliphatic C $\left(3010-2800 \mathrm{~cm}^{-1}\right)$ : $2930 \mathrm{~cm}^{-1}$; aromatic C $\left(1680-1580 \mathrm{~cm}^{-1}\right): 1620 \mathrm{~cm}^{-1}$; amide N (1546$\left.1520 \mathrm{~cm}^{-1}\right): 1530 \mathrm{~cm}^{-1}$; and polysaccharide C (1175-1148 $\left.\mathrm{cm}^{-1}\right): 1159$ $\mathrm{cm}^{-1}$. Error bars represent the standard error $(n=3)$ of a treatment 


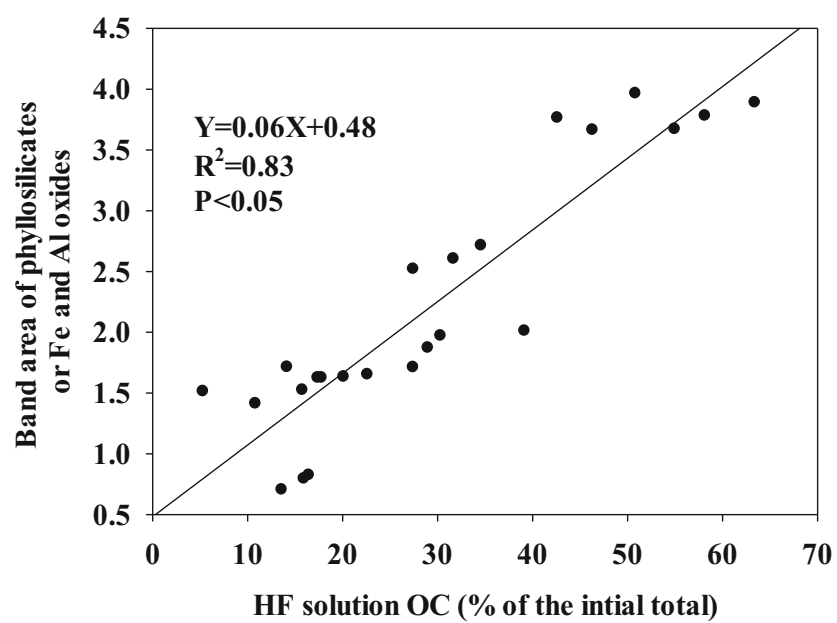

Fig. 6 Relationship between the amount of HF soluble OC and the corrected band area of mineral (phyllosilicates or Fe and Al oxides) in the infrared Fourier transform spectra of the four density fractions of control and manure treatments. Band area integration limit $=3700$ $3440 \mathrm{~cm}^{-1}$

$\mathrm{MOM}_{2.2-2.6}$, and quartz and feldspar-dominated $\mathrm{MOM}_{>} 2.6$ (Fig. 2). The decreased C:N ratio and the increased $\delta^{13} \mathrm{C}$ with higher density (Fig. 4a, c) indicated that $\mathrm{OC}$ from microbial processes is more likely to accumulate in higher density fractions (Moni et al. 2012).

The $\mathrm{MOM}_{1.8-2.2}$ and $\mathrm{MOM}_{2.2-2.6}$ retained about $80 \%$ OC and $\mathrm{N}$ of bulk soil (Table 1) and had $31.2-58.8 \%$ HFdissolved OC (Table 2), which indicated a greater potential of $\mathrm{Fe}$ and $\mathrm{Al}$ oxides and phyllosilicates to preserve and store OC. Schimel et al. (1985) also found that SOC content had a strong relationship with clay content in the soil. However, the stronger positive correlation of the HF-dissolved OC (\%) with Fe oxides than $\mathrm{Al}$ oxides (Fig. 8a) showed that $\mathrm{Fe}$ oxides play a more important role in preserving $\mathrm{OC}$ pool by organo-Fe complexes compared with $\mathrm{Al}$ oxides in red soil during manure fertilization (Rasmussen et al. 2006; Zhang et al. 2013). The reason may be because of the higher $\mathrm{pH}$ and $\mathrm{P}$ content in soil caused by manure fertilization (Table S2) going against the organo-Al association (Shen et al. 2018). The substantial reduction of band area just occurred in the aromatic $\mathrm{C}$ of the $\mathrm{MOM}_{1.8-2.2}$ and $\mathrm{MOM}_{2.2-2.6}$ after HF demineralization (Fig. $7 \mathrm{~b}$ ), which could suggest that perhaps OC associated with clay mineral in these fractions was mostly composed of aromatic $\mathrm{C}$. That is because the aromatic compounds have a high affinity for the hydroxyl group (OH-) on the surface of minerals by ligand exchange (Sollins et al. 1996). Kramer et al. (2012) also suggested that the binding of carboxyl-rich aromatic compound with short-range order mineral could be invoked to explain the persistence of $\mathrm{OC}$ in subsoil. These acidic functional groups (e.g., $\mathrm{COO}^{-}$) could be electrostatically associated with hydroxy polyvalent cations of $\mathrm{Fe}$ and $\mathrm{Al}$ oxides in acid red soil (Mikutta et al. 2007). However, in this study, it was difficult to precisely distinguish the amount and structure of these OC compounds between phyllosilicates and $\mathrm{Fe}$ and $\mathrm{Al}$ oxides in the $\mathrm{MOM}_{1.8-2.2}$ and $\mathrm{MOM}_{2.2-2.6}$ based on the existing data and methods. In future studies, X-ray photoelectron spectroscopy (XPS) and scanning transmission X-ray microscopy paired with near-edge X-ray absorption spectroscopy (STXM-NEXAFS) will be effective tools to quantitatively and qualitatively evaluate the organo-mineral complexes among phyllosilicates and $\mathrm{Fe}$ and $\mathrm{Al}$ oxides (Sowers et al. 2018).

The $\mathrm{MOM}_{>2.6}$ that comprised $37.2-38.9 \%$ soil mass merely retained $3.8-4.7 \% \mathrm{OC}$ and $7.2-8.7 \% \mathrm{~N}$ of bulk soil, and had the lowest $\mathrm{OC}$ and $\mathrm{N}$ contents (Fig. 3 and Table 1), which attributed to the quartz and feldspar with the low and

Table 2 The proportions of mass, organic carbon (OC), total nitrogen $(\mathrm{N})$, and $\mathrm{OC}$ and $\mathrm{N}$ contents and C:N ratio of the HF-dissolved organic matter in the four density fractions of control (CK) and manure (M) treatments

\begin{tabular}{|c|c|c|c|c|c|c|c|}
\hline \multirow[t]{2}{*}{ Treatments } & \multirow[t]{2}{*}{ Density fraction } & \multicolumn{3}{|c|}{$\%$ of the initial total } & \multicolumn{2}{|c|}{ Total in dissolved fraction $\left(\mathrm{g} \mathrm{kg}^{-1}\right)$} & \multirow[t]{2}{*}{$\mathrm{C}: \mathrm{N}$} \\
\hline & & Mass & $\mathrm{OC}$ & $\mathrm{N}$ & $\mathrm{OC}$ & $\mathrm{N}$ & \\
\hline \multirow[t]{4}{*}{$\mathrm{CK}$} & POM & $75.4 \pm 1.2 \mathrm{Ca}$ & $10.1 \pm 4.5 \mathrm{Ca}$ & $29.6 \pm 5.5 \mathrm{Da}$ & $16.53 \pm 7.07 \mathrm{Ab}$ & $3.34 \pm 0.60 \mathrm{Aa}$ & $4.82 \pm 1.43 \mathrm{Bb}$ \\
\hline & $\mathrm{MOM}_{1.8-2.2}$ & $89.8 \pm 0.1 \mathrm{Ba}$ & $31.3 \pm 2.9 \mathrm{Ba}$ & $48.4 \pm 5.4 \mathrm{Ca}$ & $20.75 \pm 2.19 \mathrm{Ab}$ & $2.92 \pm 0.49 \mathrm{Ab}$ & $7.28 \pm 1.72 \mathrm{Ab}$ \\
\hline & $\mathrm{MOM}_{2.2-2.6}$ & $87.2 \pm 1.6 \mathrm{Ba}$ & $46.6 \pm 4.1 \mathrm{Ab}$ & $63.1 \pm 4.1 \mathrm{Bb}$ & $4.70 \pm 0.31 \mathrm{Bb}$ & $1.20 \pm 0.06 \mathrm{Bb}$ & $3.90 \pm 0.10 \mathrm{Bb}$ \\
\hline & $\mathrm{MOM}_{>2.6}$ & $96.6 \pm 0.2 \mathrm{Aa}$ & $12.8 \pm 4.4 \mathrm{Ca}$ & $84.0 \pm 1.5 \mathrm{Aa}$ & $0.23 \pm 0.03 \mathrm{Ca}$ & $0.24 \pm 0.01 \mathrm{Ca}$ & $0.99 \pm 0.17 \mathrm{Ca}$ \\
\hline \multirow[t]{4}{*}{ M } & POM & $54.4 \pm 1.9 \mathrm{Db}$ & $6.3 \pm 0.7 \mathrm{Da}$ & $10.3 \pm 2.1 \mathrm{Cb}$ & $25.61 \pm 2.12 \mathrm{Ba}$ & $3.21 \pm 0.49 \mathrm{Ba}$ & $8.06 \pm 0.79 \mathrm{Ba}$ \\
\hline & $\mathrm{MOM}_{1.8-2.2}$ & $82.1 \pm 0.6 \mathrm{Cb}$ & $31.2 \pm 3.6 \mathrm{Ba}$ & $36.7 \pm 2.1 \mathrm{Bb}$ & $39.01 \pm 4.24 \mathrm{Aa}$ & $4.30 \pm 0.26 \mathrm{Aa}$ & $9.06 \pm 0.58 \mathrm{Aa}$ \\
\hline & $\mathrm{MOM}_{2.2-2.6}$ & $90.9 \pm 0.3 \mathrm{Ba}$ & $58.8 \pm 4.3 \mathrm{Aa}$ & $72.1 \pm 2.8 \mathrm{Aa}$ & $6.45 \pm 0.41 \mathrm{Ca}$ & $1.47 \pm 0.04 \mathrm{Ca}$ & $4.39 \pm 0.16 \mathrm{Ca}$ \\
\hline & $\mathrm{MOM}_{>2.6}$ & $96.5 \pm 0.4 \mathrm{Aa}$ & $17.7 \pm 3.2 \mathrm{Ca}$ & $78.4 \pm 0.3 \mathrm{Ab}$ & $0.22 \pm 0.03 \mathrm{Da}$ & $0.23 \pm 0.01 \mathrm{Da}$ & $0.96 \pm 0.15 \mathrm{Da}$ \\
\hline
\end{tabular}

Density fractions: $\operatorname{POM}\left(<1.8 \mathrm{~g} \mathrm{~cm}^{-3}\right), \mathrm{MOM}_{1.8-2.2}\left(1.8-2.2 \mathrm{~g} \mathrm{~cm}^{-3}\right), \mathrm{MOM}_{2.2-2.6}\left(2.2-2.6 \mathrm{~g} \mathrm{~cm}^{-3}\right)$, and MOM $>2.6\left(>2.6 \mathrm{~g} \mathrm{~cm}^{-3}\right)$. Different uppercase and lowercase letters indicate the significant difference among different density fractions (POM vs. MOM) at the same treatment and between the two treatments $(\mathrm{CK}$ vs. $\mathrm{M})$ at the same density fraction, respectively $(P<0.05)$. Values are means $(n=3)$ with standard error

$P O M$ particular organic matter, $M O M$ mineral-associated organic matter 
Fig. 7 Relative band change (\%) of four organic groups in the infrared Fourier transform spectra of the four density fractions of control (CK) and manure (M) treatments after $10 \%$ hydrofluoric acid demineralization compared with their relevant untreated sample spectra. POM, particular organic matter $\left(<1.8 \mathrm{~g} \mathrm{~cm}^{-3}\right)$; MOM, mineral-associated organic matter. $\mathrm{MOM}_{1.8-2.2}(1.8-2.2 \mathrm{~g}$ $\left.\mathrm{cm}^{-3}\right), \mathrm{MOM}_{2.2-2.6}(2.2-2.6 \mathrm{~g}$ $\left.\mathrm{cm}^{-3}\right), \mathrm{MOM}_{>2.6}\left(>2.6 \mathrm{~g} \mathrm{~cm}^{-3}\right)$. Aliphatic C (3010-2800 $\left.\mathrm{cm}^{-1}\right)$ : $2930 \mathrm{~cm}^{-1}$; aromatic C (1680$\left.1580 \mathrm{~cm}^{-1}\right): 1620 \mathrm{~cm}^{-1}$; amide $\mathrm{N}$ (1546-1520 $\left.\mathrm{cm}^{-1}\right): 1530 \mathrm{~cm}^{-1}$; and polysaccharide $\mathrm{C}(1175$ $\left.1148 \mathrm{~cm}^{-1}\right): 1159 \mathrm{~cm}^{-1}$. Different letters on the top or bottom of the error bars indicate a significant difference between the two treatments (CK vs. M) at the same density fraction $(P<0.05)$. Error bars represent the standard error $(n=3)$ of a treatment
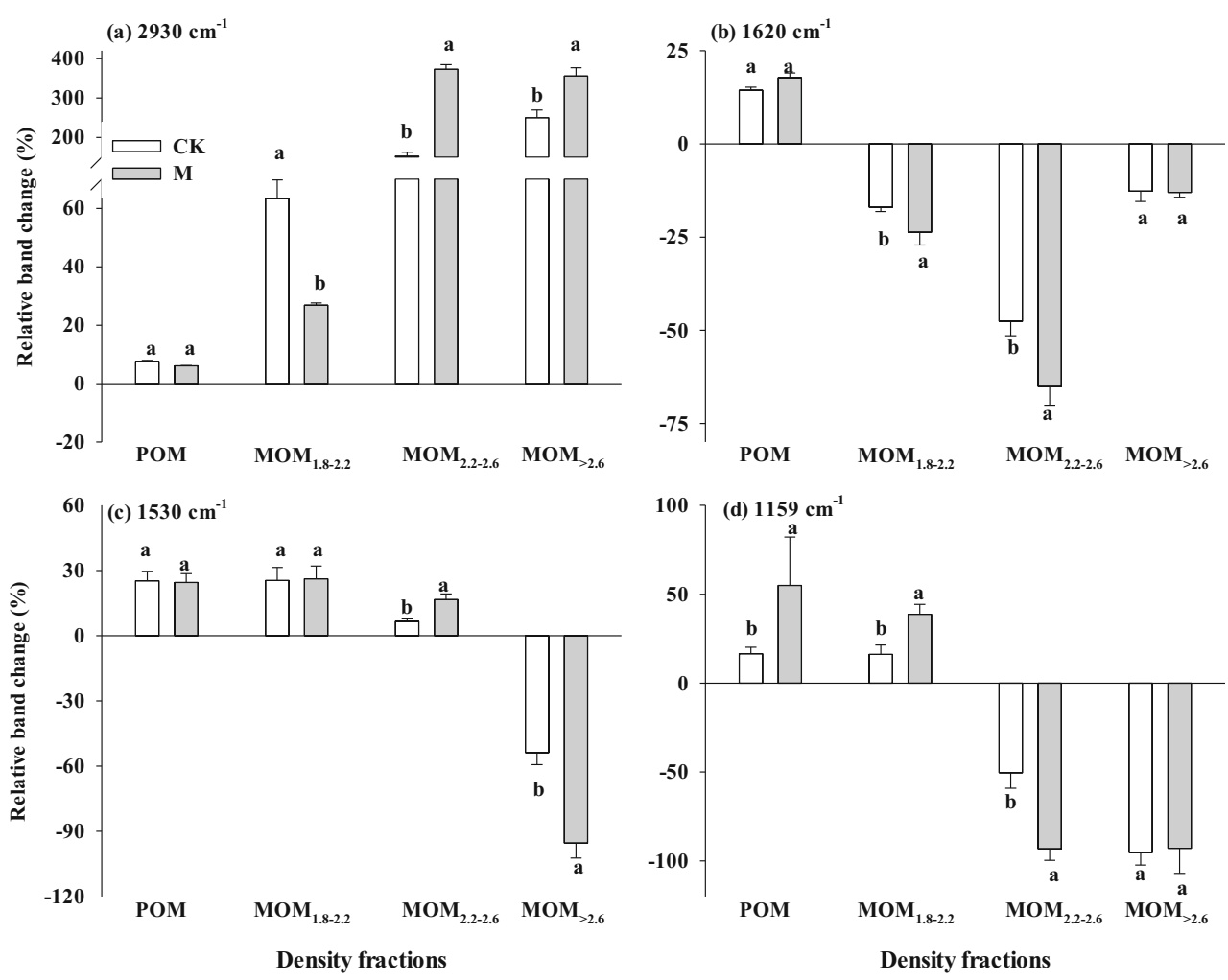

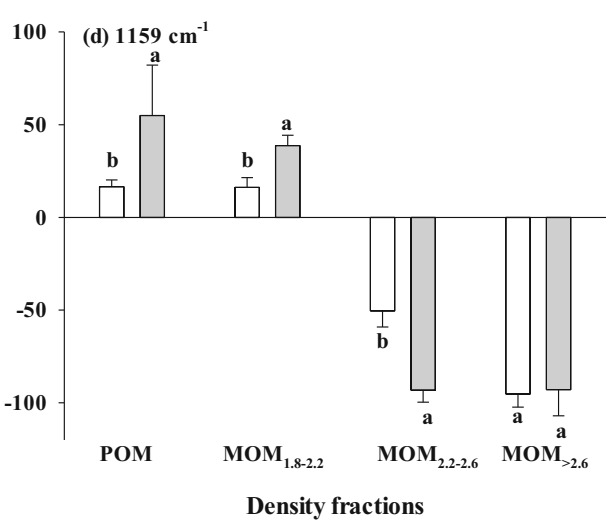

unreactive specific surface areas, low charge, and some unsatisfied siloxane bonds that contribute little to preserve and store the OC pool. On the other hand, quartz and feldspar surfaces are generally coated with $\mathrm{Fe}$ and $\mathrm{Al}$ oxides or phyllosilicate, which result in a preferential association of OC with the surfaces of $\mathrm{Fe}$ and $\mathrm{Al}$ oxides or phyllosilicate (Jones and Singh 2014). The substantial reduction in the relative band areas of aromatic C, amide N, and polysaccharides (Fig. 7b, c, d) after HF demineralization suggested that those organic functional groups could be associated with quartz or feldspars. Jindaluang et al. (2013) also reported that $>2.6 \mathrm{~g} \mathrm{~cm}^{-3}$ density fraction of coarse-textured soil with the lowest OC content enriched with aromatic $\mathrm{C}$ and amide N. Jones and Singh (2014) indicated that the bonding of OC to quartz and feldspar surface consisted of polysaccharides and protonated amide $\mathrm{N}$ compounds which might associate with unsatisfied siloxane bonds of quartz and feldspar surface by hydrogen bonding and electrostatic attraction respectively.

\subsection{Organo-mineral complex distribution and composition changes following manure fertilization}

In the POM, the increased alkyl $\mathrm{C}$ and aliphatic $\mathrm{C}$ and the decreased aromatic $\mathrm{C}$ after manure fertilization indicated that the POM structure tended to become simpler and more aliphatic (Fig. 5a, b, d). This could be explained by the fact that the POM in the M contained more undecomposed or labile swine manure and plant materials (Dou et al. 2008).
Meanwhile, this fraction had few HF-dissolved OC (Table 2) which may be due to the presence of minor encrustations of mineral grains in the POM (Moni et al. 2012; Yeasmin et al. 2017a). After all, organo-mineral association was secondary in the POM.

The dissolved organic matter derived from manure can be adsorbed by Fe oxides forming organo-mineral complexes or it can intercalate between the layers of phyllosilicates (Neff and Asner 2001; Fernández-Ugalde et al. 2017), which caused more HF-dissolved OC (Table 2) in the $\mathrm{MOM}_{1.8-2.2}$ and $\mathrm{MOM}_{2.2-2.6}$ of the $\mathrm{M}$, contributing to protection and stabilization of manure-derived OC during manure fertilization. The increased mineral bound $\mathrm{OC}$ content as a result of manure application affected the OC chemical structure when compared with $\mathrm{CK}$. The polysaccharides associated with $\mathrm{MOM}_{2.2-2.6}$ in the $\mathrm{M}$ were substantially reduced after the HF demineralization than in the CK (Fig. 7d), indicating that organic fertilization could promote the bonding of polysaccharides with Fe oxides or phyllosilicates. During the degradation of manure, the produced carbohydrate can strongly absorb on Fe oxides or phyllosilicates through cation bridge or hydrogen bonding (von Lützow et al. 2006). Furthermore, manure fertilization could also make the $\mathrm{OC}$ associated with $\mathrm{MOM}_{2.2-2.6}$ more aromatic (the higher aromatic $\mathrm{C}$ :aliphatic $\mathrm{C}$ ratio in the M) (Fig. 5e), as further supported by the substantial reduction of aromatic $\mathrm{C}$ following $\mathrm{HF}$ demineralization in the $\mathrm{MOM}_{1.8-2.2}$ and $\mathrm{MOM}_{2.2-2.6}$ of the $\mathrm{M}$ compared with the $\mathrm{CK}$ (Fig. 7b). This may be due to the highly oxidized tannins, 

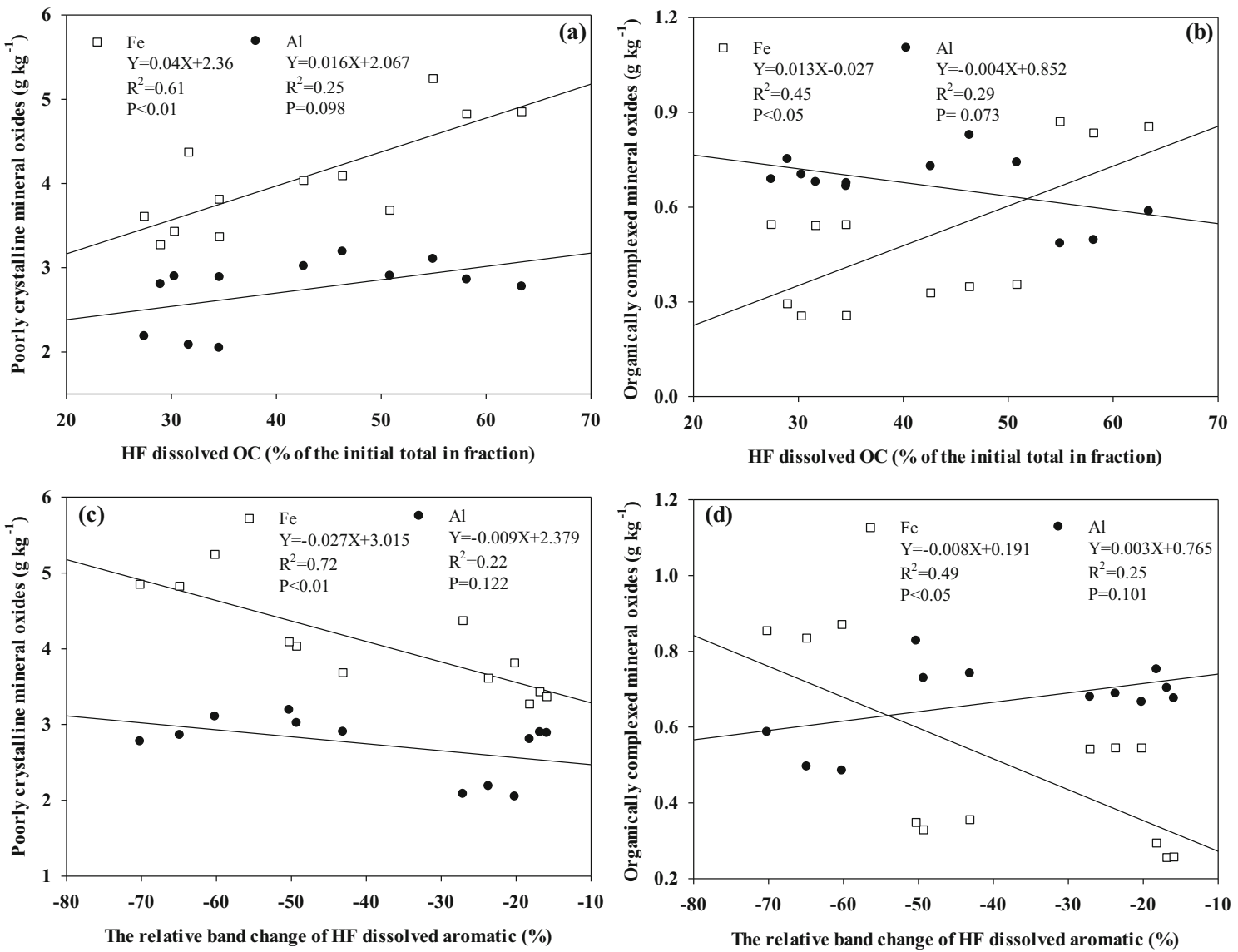

Fig. 8 Relationship of the proportions of HF-dissolved OC (\%) with poorly crystalline (a) and organically complexed $\mathrm{Fe}$ and $\mathrm{Al}\left(\mathrm{g} \mathrm{kg}^{-1}\right)(\mathbf{b})$ and relationship of the relative band change of aromatic $\mathrm{C} \mathrm{( \% )} \mathrm{after} 10 \%$ hydrofluoric acid demineralization with poorly crystalline (c) and

organically complexed $\mathrm{Fe}$ and $\mathrm{Al}\left(\mathrm{g} \mathrm{kg}^{-1}\right)$ (d) in $\mathrm{MOM}_{1.8-2.2}$ and $\mathrm{MOM}_{2.2-2.6}$ of the control and manure treatments. MOM, mineralassociated organic matter. $\mathrm{MOM}_{1.8-2.2}\left(1.8-2.2 \mathrm{~g} \mathrm{~cm}^{-3}\right), \mathrm{MOM}_{2.2-2.6}$ $\left(2.2-2.6 \mathrm{~g} \mathrm{~cm}^{-3}\right)$

polyphenols, and other aromatic compounds derived from decomposed manure bind directly to hydroxylated mineral surface (Kleber et al. 2007). Similarly, aromatic lignin constituents could be specifically stabilized during Fe addition to soil (Hall et al. 2016).

In the present study, the higher contents of poorly crystalline and organically complexed $\mathrm{Fe}$ oxides in the $\mathrm{MOM}_{1.8-2.2}$ and $\mathrm{MOM}_{2.2-2.6}$ of the $\mathrm{M}$ than $\mathrm{CK}$ (Fig. 3a, b) indicated that organic fertilization could increase the mineral availability and promote the formation of organo-Fe complexes. The reason is the fact that organic acid derived from decomposed manure could drive the transformation of Fe oxides from crystalline to short-range order and the formed organo-Fe complexes can stand up to Fe recrystallization (Yu et al. 2017; Huang et al. 2018); another reason is that the near-neutral $\mathrm{pH}$ conditions under the M (Table S2) promote the precipitation and stabilization of short-range order Fe minerals (Colombo et al. 2014). These increased $\mathrm{Fe}$ oxides were significantly negatively correlated with the relative band area of HF-dissolved aromatic $\mathrm{C}$ (\%) $\left(R^{2}=0.72, P<0.01\right.$ for poorly crystalline $\mathrm{Fe} ; R^{2}=0.49, P$ $<0.05$ for organically complexed Fe) (Fig. 8c, d), suggesting that manure fertilization could increase the formation of

aromatic OC-Fe complexes, which contributed to the SOC preservation in red soil. This is consistent with preferential association between the poorly crystalline Fe oxide mineral and aromatic organic compounds in soil (Kramer et al. 2012; Huang et al. 2018). Adhikari et al. (2017) also investigated the release and transformation of ferrihydrite-bound OC during microbial $\mathrm{Fe}$ reduction and found that the transformation of non-crystalline ferrihydrite to crystalline Fe phases was dependent on the $\mathrm{OC} / \mathrm{Fe}$ ratio, and aromatic $\mathrm{OC}$ was preferentially retained within OC-ferrihydrite co-precipitation. In our study, the accumulation of decomposed swine manure rich in aromatic $\mathrm{C}$ under manure fertilization facilitated aromatic OCpoorly crystalline $\mathrm{Fe}$ oxide association, which promoted the role of organo-Fe complexes in SOC preservation in red soil.

It should be noted that, in this study, we studied the composition of organo-mineral complexes in each density fraction merely depending on some quantity relations between the contents of minerals and the changes of organic functional group areas obtained from FTIR analysis after and before HF demineralization, which could interpret partial information of organo-mineral complexes, but less adequate for elaborating the bonds of organo-mineral. Therefore, further 
investigation on organo-mineral complexes under soil incubation with ${ }^{13} \mathrm{C}$-labeled organic matters, and together with nanoscale secondary ion mass spectroscopy, XPS, and STXM-NEXAFS, may validate how mineral oxides associated with SOC in red soil.

\section{Conclusions}

The SDF and HF demineralization methods, together with chemical characterization using FTIR spectrometer, can be used to assess the effect of manure fertilization on the quality and quantity of organo-mineral complexes within different density fractions of red soil. Manure fertilization could significantly improve the OC and $\mathrm{N}$ contents of POM, $\mathrm{MOM}_{1.8-2.2}$, and $\mathrm{MOM}_{2.2-2.6}$. The $\mathrm{Fe}$ and $\mathrm{Al}$ oxides and phyllosilicatedominated $\mathrm{MOM}_{1.8-2.2}$ and $\mathrm{MOM}_{2.2-2.6}$ contributed to 82.9$86.1 \%$ of SOC, of which Fe bound OC played the most vital role in SOC stabilization and was susceptible to fertilization. Manure fertilization significantly increased the contents of poorly crystalline and organically complexed Fe oxides within the $\mathrm{MOM}_{1.8-2.2}$ and $\mathrm{MOM}_{2.2-2.6}$ and then facilitated the formation of aromatic OC-Fe complex $(P<0.05)$, which contributed to the OC preservation in red soils. The quartz and feldspar-dominated $\mathrm{MOM}_{>2.6}$, containing aromatic $\mathrm{C}$, amide $\mathrm{N}$, and polysaccharides, merely retained $3.8-4.7 \%$ of SOC and had less contribution to the OC preservation, not being affected by fertilization. Although this study contributes some knowledge on potential preservation mechanisms of OC in red soils, one soil type (single red soil) and two treatment (control and manure fertilization) are not enough to draw some general laws and conclusions, especially the interactions between minerals and specific organic compounds. Further studies will focus on turnover times and molecular compositions of organo-mineral complexes under different fertilizer applications (e.g., inorganic fertilizer, different kinds of straws returning) and soil types (e.g., luvisol, mollisol, and vertisol).

Funding This work was financially supported by the National Natural Science Foundation of China (Grant no. 41671308 and no. U19A2048) and the Science Innovation Project of the Chinese Academy of Agricultural Science (CAAS-ASTIP-2016-IEDA).

\section{References}

Adhikari D, Zhao Q, Das K, Mejia J, Huang RX, Wang XL, Poulson SR, Tang YZ, Roden EE, Yang Y (2017) Dynamics of ferrihydritebound organic carbon during microbial $\mathrm{Fe}$ reduction. Geochim Cosmochim Acta 212:221-233

Bruun TB, Elberling B, Christensen BT (2010) Lability of soil organic carbon in tropical soils with different clay minerals. Soil Biol Biochem 42(6):888-895
Colombo C, Palumbo G, He J, Pinton R, Cesco S (2014) Review on iron availability in soil: interaction of Fe minerals, plants, and microbes. J Soils Sediments 14(3):538-548

Dakora F, Phillips D (2002) Root exudates as mediators of mineral acquisition in low-nutrient environments. Plant Soil 245(1):35-47

Demyan MS, Rasche F, Schulz E, Breulmann M, Müller T, Cadisch G (2012) Use of specific peaks obtained by diffuse reflectance Fourier transform mid-infrared spectroscopy to study the composition of organic matter in a Haplic Chernozem. Eur J Soil Sci 63(2):189-199

Dou S, Zhang JJ, Li K (2008) Effect of organic matter applications on ${ }^{13}$ C-NMR spectra of humic acids of soil. Eur J Soil Sci 59(3):532539

Fernández-Ugalde $\mathrm{O}$, Gartzia-Bengoetxea N, Arostegi J, Moragues L, Arias-González A (2017) Storage and stability of biochar-derived carbon and total organic carbon in relation to minerals in an acid forest soil of the Spanish Atlantic area. Sci Total Environ 587:204 213

Filimonova S, Kaufhold S, Wagner FE, Hausler W, Kogelknabner I (2016) The role of allophane nano-structure and $\mathrm{Fe}$ oxide speciation for hosting soil organic matter in an allophanic Andosol. Geochim Cosmochim Acta 180:284-302

Hall SJ, Silver WL, Timokhin VI, Hammel KE (2016) Iron addition to soil specifically stabilized lignin. Soil Biol Biochem 98:95-98

Helfrich M, Flessa H, Mikutta R, Dreves A, Ludwig B (2007) Comparison of chemical fractionation methods for isolating stable soil organic carbon pools. Eur J Soil Sci 58(6):1316-1329

Huang X, Tang H, Kang W, Yu G, Ran W, Hong J, Shen Q (2018) Redox interface-associated organo-mineral interactions: a mechanism for $\mathrm{C}$ sequestration under a rice-wheat cropping system. Soil Biol Biochem 120:12-23

Jindaluang W, Kheoruenromme I, Suddhiprakarn A, Singh BP, Singh B (2013) Influence of soil texture and mineralogy on organic matter content and composition in physically separated fractions soils of Thailand. Geoderma 195:207-219

Jones E, Singh B (2014) Organo-mineral interactions in contrasting soils under natural vegetation. Front Environ Sci 2:2

Kaiser K, Eusterhues K, Rumpel C, Guggenberger G, Kögel-Knabner I (2002) Stabilization of organic matter by soil mineralsinvestigations of density and particle-size fractions from two acid forest soils. J Plant Nutr Soil Sci 165(4):451-459

Kleber M, Sollins P, Sutton R (2007) A conceptual model of organomineral interactions in soils: self-assembly of organic molecular fragments into zonal structures on mineral surfaces. Biogeochemistry 85(1):9-24

Kramer MG, Sanderman J, Chadwick OA, Chorover J, Vitousek PM (2012) Long-term carbon storage through retention of dissolved aromatic acids by reactive particles in soil. Glob Chang Biol 18 (8):2594-2605

Lal R (2018) Digging deeper: a holistic perspective of factors affecting soil organic carbon sequestration in agroecosystems. Glob Chang Biol 24(8):3285-3301

Lavallee JM, Soong JL, Cotrufo MF (2020) Conceptualizing soil organic matter into particulate and mineral-associated forms to address global change in the 21st century. Glob Chang Biol 26:261-273

McKeague JA, Brydon JE, Miles NM (1971) Differentiation of forms of extractable iron and aluminum in soils 1. Soil Sci Soc Am J 35(1): 33-38

Mikutta R, Mikutta C, Kalbitz K, Scheel T, Kaiser K, Jahn R (2007) Biodegradation of forest floor organic matter bound to minerals via different binding mechanisms. Geochim Cosmochim Acta 71 (10):2569-2590

Moni C, Derrien D, Hatton PJ, Zeller B, Kleber M (2012) Density fractions versus size separates: does physical fractionation isolate functional soil compartments? Biogeosciences 9(12):5181-5197

Neff JC, Asner GP (2001) Dissolved organic carbon in terrestrial ecosystems: synthesis and a model. Ecosystems 4(1):29-48 
Rasmussen C, Southard RJ, Horwath WR (2006) Mineral control of organic carbon mineralization in a range of temperate conifer forest soils. Glob Chang Biol 12:834-847

Reeves DW (1997) The role of soil organic matter in maintaining soil quality in continuous cropping systems. Soil Tillage Res 43(1-2): 131-167

Rumpel C, Chaplot V, Chabbi A, Largeau C, Valentin C (2008) Stabilisation of $\mathrm{HF}$ soluble and $\mathrm{HCl}$ resistant organic matter in sloping tropical soils under slash and burn agriculture. Geoderma 145(34):347-354

Sanderman J, Farrell M, Macreadie PI, Hayes MA, Mcgowan J, Baldock J (2017) Is demineralization with dilute hydrofluoric acid a viable method for isolating mineral stabilized soil organic matter. Geoderma 304:4-11

Schimel D, Coleman D, Horton K (1985) Soil organic matter dynamics in paired rangeland and cropland toposequences in North Dakota. Geoderma 36:201-214

Shen Q, Suarez-Abelenda M, Camps-Arbestain M, Calvelo Pereira R, Mcnally SR, Kelliher FM (2018) An investigation of organic matter quality and quantity in acid soils as influenced by soil type and land use. Geoderma 328:44-55

Six J, Conant RT, Paul EA, Paustian K (2002) Stabilization mechanisms of soil organic matter: implications for $\mathrm{C}$-saturation of soils. Plant Soil 241(2):155-176

Sleutel S, Leinweber P, Begum SA, Kader MA, De Neve S (2009) Shifts in soil organic matter composition following treatment with sodium hypochlorite and hydrofluoric acid. Geoderma 149(3-4):257-266

Soil Survey Staff (2010) Keys to soil taxonomy, 11th edn. USDA, Washington, D.C.

Sollins P, Homann P, Caldwell BA (1996) Stabilization and destabilization of soil organic matter: mechanisms and controls. Geoderma 74: 65-105

Sollins P, Kramer MG, Swanston C, Lajtha K, Filley T, Aufdenkampe AK, Wagai R, Bowden RD (2009) Sequential density fractionation across soils of contrasting mineralogy: evidence for both microbialand mineral-controlled soil organic matter stabilization. Biogeochemistry 96(1-3):209-231

Sowers TD, Adhikari D, Wang J, Yang Y, Sparks DL (2018) Spatial associations and chemical composition of organic carbon sequestered in $\mathrm{Fe}, \mathrm{Ca}$, and organic carbon ternary systems. Environ Sci Technol 52(12):6936-6944
Tong X, Xu M, Wang X, Bhattacharyya R, Zhang W, Cong R (2014) Long-term fertilization effects on organic carbon fractions in a red soil of China. Catena 113:251-259

Torn MS, Trumbore SE, Chadwick OA, Vitousek PM, Hendricks DM (1997) Mineral control of soil organic carbon storage and turnover. Nature 389:170-173

von Lützow M, Kögel-Knabner I, Ekschmitt K, Matzner E, Guggenberger G, Marschner B, Flessa H (2006) Stabilization of organic matter in temperate soils: mechanisms and their relevance under different soil conditions-a review. Eur J Soil Sci 57(4):426445

Wagai R, Kajiura M, Asano M, Hiradate S (2015) Nature of soil organomineral assemblage examined by sequential density fractionation with and without sonication: is allophanic soil different? Geoderma 241:295-305

Wan D, Ye TH, Lu Y, Chen WL, Cai P, Huang QY (2019) Iron oxides selectively stabilize plant-derived polysaccharides and aliphatic compounds in agricultural soils. Eur J Soil Sci 70(6):1153-1163

Yeasmin S, Singh B, Johnston CT, Sparks DL (2017a) Evaluation of pretreatment procedures for improved interpretation of mid infrared spectra of soil organic matter. Geoderma. 304:83-92

Yeasmin S, Singh B, Johnston CT, Sparks DL (2017b) Organic carbon characteristics in density fractions of soils with contrasting mineralogies. Geochim Cosmochim Acta 218:215-236

Yu GH, Xiao J, Hu SJ, Polizzotto ML, Zhao FJ, Mcgrath SP, Li H, Ran W, Shen QR (2017) Mineral availability as a key regulator of soil carbon storage. Environ Sci Technol 51(9):4960-4969

Zhang HM, Wang BR, Xu MG, Fan TL (2009) Crop yield and soil responses to long-term fertilization on a red soil in southern China. Pedosphere 19(2):199-207

Zhang JC, Zhang L, Wang P, Huang QW, Yu GH, Li DC, Shen QR, Ran W (2013) The role of non-crystalline Fe in the increase of SOC after long-term organic manure application to the red soil of southern China. Eur J Soil Sci 64(6):797-804

Zhao Q, Poulson SR, Obrist D, Sumaila S, Dynes JJ, McBeth JM, Yang Y (2016) Iron-bound organic carbon in forest soils: quantification and characterization. Biogeosciences 13:4777-4788

Publisher's note Springer Nature remains neutral with regard to jurisdictional claims in published maps and institutional affiliations. 